\title{
THE AGENDA FOR CHANGE
}

\author{
James Moeser, Ph.D., Chancellor \\ University of Nebraska - Lincoln
}

I want to thank KU's Merrill Advanced Studies Center for convening this conference and for the opportunity to participate in it. It is a rare opportunity for a chancellor to sit with and listen to faculty, to hear them talk about their work, their aspirations, their fears and anxieties, and their dreams. It is an opportunity to be reminded of the real purpose of the university.

I hope that there will be future conferences like this one and that there will be greater opportunities for faculties from Nebraska, Missouri, and Oklahoma to join their colleagues at Kansas for more dialogues such as these. I am convinced that we must begin to engage faculties in these discussions.

I also want to thank the Center for focusing on these four universities and encourage you to continue the dialogue with these four institutions that are so similar in size, scope, mission, and relative quality, as well as sharing the contiguous heartland of America, often regarded as removed and remote from the centers of power and excellence on the coasts. I believe we have much to learn from one another and much to contribute to each other.

I have had the benefit of being able to listen to the presentations that have been made during this day and a half, and I would like to use my time, in part, to recapitulate some of what I heard. First, from Paul Cheney's presentation, I would like to repeat a quotation that he used at the very beginning of his presentation:

"The institutions that will succeed are those that can reorganize themselves to address scientific and educational questions in an interdisciplinary manner. The institutions that will have difficulty are the ones that keep the same rigid structure that prevents pollination among disciplines." (Mark Rodgers, Vice Chancellor for Health Affairs, Duke University, from The Scientist, 1995.)

If that statement is true for Duke, how much more true is it for Nebraska, or Kansas, or Oklahoma, or Missouri? It is a sobering statement, but I believe it is absolutely on the mark. We must change to survive. One of my colleagues has said that universities that fail to change will not necessarily disappear. Rather, they will be like the drive-in movie theatres still found on the outskirts of small towns in America -- still there, but very poorly attended.

Eli Michaelis described the two factors that motivate researchers as uncertainty and urgency. He also spoke candidly and revealingly about his own fear of failure, something that I appreciated very much. I will tell you that chancellors and presidents are motivated by these same factors, and if we are honest with ourselves, we live every day with the risk of failure. To attempt great things is to risk failure. The greater the attempt, the greater the risk. I believe that 
we have an enormous challenge ahead of us, and the possibility of failure is very great. Yet, we must not be afraid to lead for fear of failure. That, in itself, would be the greatest failure of all.

Someone once said that a chancellor is a person who lives in a big house and begs for a living. A more recent definition, by former president James Duderstadt of the University of Michigan, is that a president is somewhat like the sheriff of the Old West, who every morning straps on his six-shooter and walks into town knowing that some morning he is going to meet someone who can draw faster than he does. That is another way of saying that we have a finite amount of political capital, and that with each crisis, we spend a certain amount of that capital, until it is gone.

The times that lie ahead will require expenditures of great amounts of political capital if we are to achieve what I think we need to do. But first let us examine the context in which we find ourselves.

American higher education is entering a very difficult period. The modern research establishment was built by the federal government during the Second World War as a means of prosecuting the war. With the advent of the Cold War, American science and technology, largely placed in research universities, was charged with keeping the West ahead of the Soviets. While aimed at supporting primarily science and technology, even the arts and the humanities benefited from this investment. Students at the University of Kansas are still practicing today on a fine Casavant tracker organ that we purchased using National Defense Education Act funds. I had several graduate students in music performance supported on NDEA grants -- learning to play Bach in the name of national defense!

Now, however, the Cold War is over, and a primary political impetus for research support has disappeared. More serious is the growing pressure on the discretionary portion of the federal budget, due to the inexorable growth of payments toward the national debt as well as the growing cost of social entitlements. Even with a strong will to maintain federal support for research, it is going to be difficult to find the financial means to do so as the noose tightens around the discretionary portion of the budget.

All across the nation we see growing hostility toward universities and faculty in state legislatures and in our governing boards. We often blame the politicians for their lack of understanding of what we are about, but when we do, we fail to realize that these elected officials are merely reflecting the popular opinion of the voters. Our fundamental problem is with the people themselves -- people who no longer regard universities or university faculty as above reproach.

What we see are more demands for accountability; more demands for faculty productivity (and this means productivity in the classroom, not the laboratory). They regard faculty as a kind of privileged elite, a new leisure class, with the protections of life-time job security available in almost no other sector of society. In an age of tremendous insecurity and anxiety over corporate downsizing and job elimination, faculty are increasingly viewed as somewhat arrogantly maintaining a level of privilege and security not enjoyed by others, all the while not working 
very hard either. Thus, we see attacks on tenure and sabbatical leaves, and demands that we increase the amount of time faculty spend in the classroom.

Meanwhile, state budgets are facing pressures very similar to those at the federal level. Indeed, as the federal government passes down many of its responsibilities to the states, usually without the funding attached, states are scrambling to find resources to support social programs previously carried by the federal government. Mandatory sentencing laws and increased crime are causing a building boom in new prisons. Community colleges and K-12 education, both affected by reductions in property taxes, come with hats in hands to their respective state capitals.

Universities now face new sources of competition -- from corporate in-house graduate training programs, to for-profit educational institutions such as the University of Phoenix. This competition for both instructional and research functions will continue to grow. Increasingly, we will be competing with each other, as state boundaries become essentially meaningless in an age of web-based or satellite-based delivery.

All of these factors require the university to be more adaptable, flexible, and responsive to the needs of the private sector; more responsive to the needs of the taxpayers who ultimately determine state policy. These taxpayers' primary interest is that their children, our students, receive our undivided attention when they enter our classrooms. And increasingly, the taxpayers are themselves students, who want just-in-time delivery of courses to their home or office; they want to be well-served. Thus, becoming a "student-centered" university takes on an entirely new definition. It begins to suggest a whole new level of service orientation.

While this is a conference on research, I have spent much of this time on teaching because I want to drive home the point that this is the total focus of local and state support. We will ignore this issue at our great peril to continued state support. (It so happens that I think it is the right thing to do anyway.)

While the residents of our respective states tend to regard us by how well they think we are doing as teaching institutions, our national colleagues measure us by our research credentials. Clearly, we need to do a better job of reinforcing the link between these two enterprises, that it is the research we do that makes the teaching possible; that what we are really about is learning, an ongoing activity that engages college freshmen and full professors.

There is one avenue of political and popular support for research at the state level, and we discussed this in several of our sessions. That is the avenue of economic development. We like to say that we are the engines of economic development, and as some correctly pointed out, while we must be careful not to overstate this assertion or make broad statements that we cannot support, I think we can find ample examples to demonstrate how this is true for each of us in our respective situations. And while this is a helpful argument, it is not strong enough, in my opinion, to carry the day to create a strong reservoir of political support at the state level for research. 


\section{The Agenda for Change}

If we are going to survive and be effective, it seems to me that we have to be willing to examine some heretofore sacred cows. Several of these were mentioned in the discussions preceding this presentation:

Academic departments may cease to be relevant except as a means of organizing undergraduate instruction, and even there I think we have to continually look at their structure. Knowledge just does not fit easily into the pigeon holes that we have created and continue to maintain. In many fields, the most exciting work is being done at the margins and at the places where the disciplines overlap. It is being done by academics who are often regarded by their departmental colleagues as working outside the traditional field and, therefore, of questionable utility to the department. These people often have difficulty getting tenure because they are thinking and working outside the box.

Tenure itself has got to be questioned. We are seeing widespread implementation of various forms of post-tenure review across the country. What about more flexible tenure clocks that recognize the sometimes unique circumstances that individuals, especially women and people working in non-traditional or interdisciplinary fields, may require in order to succeed. Ultimately, I see more and more junior faculty questioning the process itself. Do we really need it? Is it forcing a kind of regimen upon us that, in fact, suppresses creativity and encourages conformity?

Perhaps most difficult of all, is the whole process by which we have traditionally governed ourselves. Faculty governance is a central value in our institutions. We like to say that the faculty are the university, and I believe this to be a fundamental truth. Yet, in fact, we have created a system of academic bureaucracy, of layers of faculty committees and a central parliamentary body known as the faculty senate.

I cut my teeth as a member of the faculty senate at the University of Kansas. In those days it was led by the most outstanding members of the faculty. My mentors were Charlie Oldfather, Ambrose Saricks, Del Shankel, and Ron Calgaard, among others. Being elected to the senate was a matter of some prestige and honor.

Today, too many of our best faculty refuse to participate in faculty governance. They view it as an exercise in empty rhetoric and wasted time on an endless succession of committees reporting to other committees. They have pressing research agendas and students, both graduate and undergraduate, who need their time. The result is that we have faculty senates made up of those who are coerced by their colleagues into service and do so grudgingly or those who have some personal political agenda to pursue.

The challenge for us, I believe, is to find a way to re-engage the faculty in a real discussion about the nature of the academy -- what we are and what we need to become -- for I am convinced that unless we do so, we will not be able to effect fundamental change. 


\section{The Agenda for Research}

My discussion of research is based on two assumptions. The first one is that our national reputations as universities is based on the perceived quality of our faculty and our research programs.

The second assumption is that most of the departments at Nebraska (and I would imagine at the other three institutions) are too small to compete head-on with the Michigans and Berkeleys of the world. If one examines the NRC rankings of doctoral programs, one cannot escape the fact that there is a correlation between size and perceived quality.

Therefore, I believe at the University of Nebraska we must create large research clusters if we are going to create programs of national quality. Our Department of Chemistry or our Department of Physics is simply not going to be able to compete with a department that is three, four, or five times larger in faculty headcount, operating budget, number of graduate students, etc. However, if we are clever, we can create some unique clusters that will have that kind of mass and quality. That has got to be the strategy at institutions like ours.

In order to do this, we must look hard at all of our Ph.D. programs and begin to trim back those that are of marginal quality and divert the resources that support them to help build these clusters of strength. Some programs may need to be eliminated; others can simply be reduced in size and scope.

Why should we maintain a third-tier Ph.D. program? Where are the graduates of that program going to go when the Ph.D. graduates of the first-tier schools are taking positions at second- and third-tier schools? In the past, we have always been able to build strength through growth in the budget. There was always new money coming in -- in the form of enrollment growth, or federal grant support growth. In this new environment, we have to learn to do something that we have never done well at all, namely, begin to shut down some things that we do not do well, or that are no longer needed as they once were.

This will not be easy. Programs that are threatened typically mobilize a strategy to wear down the moves to eliminate or reduce. More times than not, these strategies work. The catalogues of our universities are filled with programs that survived previous attempts to trim offerings.

So far at Nebraska, we have chosen to move cautiously and incrementally, chipping away at the margins in order to free up funds for investment in areas of strength. We will reallocate approximately $\$ 6$ million over the coming biennium, or approximately $4 \%$ of the state-aided budget.

Part of our strategy involves enhancing the revenue stream, which we are seeking to do through the Capital Campaign, and which we have done with a new agreement with Pepsi Cola, which will provide about $\$ 25$ million to the university over ten years, including an $\$ 11$ million contribution to the foundation for academic enhancements. We believe we can continue to push up the level of funded research even in this more difficult and competitive climate, and we believe we can dramatically increase the income from royalties and patents. 


\section{The Message}

Since I came to Nebraska a year and a half ago, I have taken a very simple message to the people in an attempt to build support for the university. Included in this message, is support for research. It is a very simple message, with three points:

First, we must keep the best and brightest in Nebraska, at Nebraska. This speaks to the need to be the institution of choice for the brightest high school students in the state. We have just implemented new selective admissions standards for the first time, and this, together with a focused program of recruiting top scholars, is sending a strong and clear message of academic quality.

Second, I have been telling Nebraskans that if they can have the number one program in football, they can and should also have some number one academic programs. This should be a matter of state pride. Here is where I begin to describe the focusing on a few programs of national level eminence. I talk about our internal reallocations and point out that we are trying to be good stewards of our state appropriations rather than asking for new allocations to support this effort, and I work in a pitch for the Capital Campaign. You never know who's listening.

Finally, I talk about recovering our responsibility as a public university to help our students develop character and values. I describe this both in terms of an individual ethic that involves integrity and responsibility and a societal ethic that values pluralism, diversity, and a respect for others.

I will tell you that I believe we are being successful in building support within the state for the university. So far, we have been successful in maintaining the trust of the faculty as we move to focus the resources of the institution toward those areas where we can make a mark nationally.

My uncertainty, my anxiety, and to use Eli's other term, my sense of urgency, is that we must push harder and faster, and the risk is that we will not be able to convince our own colleagues that this is what we must do. My fear is that if we are unsuccessful in that regard, at that moment we will begin to become marginalized as an institution. We will begin to lose ground. My hope is that the ferment and creativity that I found at the conference at the Barn can begin to spread among more and more.

What so stimulated me at this conference was the enjoyment of thinking together creatively. Our best research faculty are creative by nature; they work at the cutting edges of their fields. If we can only engage those minds and that creativity to work on the problem of how to reform the academy, we will be in good hands. 